Eixo Temático: Educação Não-Formal

\title{
ET-08-006 \\ EDUCAÇÃO AMBIENTAL E DIREITOS HUMANOS NO ASSENTAMENTO NOVA VIDA, PITIMBU-PB
}

Josefa Vênus de Amorim, Suelen Cláudia Barbosa Lopes, Elisângela de Araújo Barbosa

Universidade Federal da Paraíba - UFPB.

http://dx.doi.org/10.21472/congrebio2016.et-08-006

\section{RESUMO}

O homem enquanto ser de relação e interação, de significação e transformação se relaciona com a natureza e nela interage e modifica, dando a ela significados que dependem da época e do lugar em que vive. Porém o homem que transforma, destrói, mas também constrói. Compreender a natureza da relação meio ambiente, direitos humanos e assentamentos rurais, com temas abordados com os assentados, como o lixo, cuidado com a água, a pesca, reciclagem e outros temas, tendo como veículo à educação e consciência ambiental com participação responsável e eficaz na prevenção e solução de problemas ambientais, onde os desafios são constantes. Procedimentos metodológicos foram utilizados na experiência com o grupo dos assentados em Pitimbu-PB, na qual foram aplicadas oficinas e aulas expositivas com exemplos práticos da necessidade do cuidar do meio ambiente para benefícios atuais e futuros do entorno, como fator de equilíbrio vital, social, psicossocial, na antropologia do imaginário, bibliografias que tenham função do objeto de pesquisa. Os resultados explicitam a necessidade da interdisciplinaridade na educação.

Palavras-chave: Educação Ambiental; Direitos Humanos; Assentamentos.

\section{INTRODUÇÃO}

O homem enquanto ser de relação e interação, de significação e transformação se relaciona com a natureza e nela interage e modifica, dando a ela significados que dependem da época e do lugar em que vive. Porém o homem que transforma, destrói, mas também constrói.

Os assentamentos rurais são áreas destinadas à reforma agrária. Terras improdutivas ou com outra irregularidade podem ser desapropriadas e destinadas para instalação de assentamentos. Terras devolutas também podem ser utilizadas para o mesmo fim. É importante destacar que os proprietários não perdem a terra; eles recebem o valor de sua propriedade e das construções realizadas. As áreas desapropriadas são destinadas a famílias que têm interesse em trabalhar no campo. Elas não ganham a terra; mas tem um plano especial de financiamentos e crédito, e um prazo para pagar. As propriedades em assentamentos não podem ser vendidas. As famílias assentadas podem ou não estar ligadas a um movimento de luta pela terra.

Eis a razão pela qual devemos adotar medidas integradas para prevenir, reduzir ou compensar a deteriorização do meio ambiente, pois este é tão necessário às sociedades contemporâneas quanto ao futuro das próximas gerações. Assim, conscientes de que, antes de sermos seres humanos, somos seres naturais cabe a cada individuo e a coletividade a cooperação mútua e ações sistematicamente preparadas para resolução dos problemas ambientais presentes e futuros.

Com participação, criatividade, espírito crítico, compreensão dos problemas, busca de soluções, sensibilização e mobilização, o homem deve realizar um trabalho interdisciplinar, construindo conhecimentos e procedimentos que possam prepará-lo para as tomadas de decisões sobre os grandes impasses com os quais nos deparamos enquanto indivíduos que dependem do 
mesmo meio para atingir uma melhor qualidade de vida. Convém também destacar que tal preocupação também se faz presente nos ordenamentos jurídicos e em alguns documentos legais.

Como fazemos parte da natureza, somos também responsáveis pela construção de um meio ambiente saudável e ecologicamente equilibrado. Leão e Silva (1999), compreende ambiente como sendo a totalidade do planeta e os elementos que o compõem: físicos, químicos e biológicos, tanto os naturais quanto os artificiais, tanto os orgânicos quanto os inorgânicos, nos distintos níveis de sua evolução.

Disso resulta que o homem é parte constitutiva desse ambiente, uma vez que está em relação direta com os demais elementos da natureza. O processo evolutivo demonstra como o meio ambiente é capaz de definir alguns caracteres essenciais do ser humano em sua dimensão racional, emocional, e biológica. Há uma reciprocidade entre as esferas do social e do natural na constituição do homem e do seu percurso histórico.

O nosso trabalho tem como objetivo investigar a relação entre Direitos Humanos e Educação Ambiental, no assentamento de Pitimbu-PB, a fim de mostrar que a defesa do meio ambiente representa, em última análise, a defesa da dignidade, do bem-estar, da vida dos indivíduos. Ademais, tentamos mostrar que o tema Educação Ambiental e Direitos Humanos é fundamental para construção da cidadania, sensibilização e consciência do indivíduo acerca da interação dinâmica entre sociedade e natureza.

\section{OBJETIVOS GERAIS}

Investigar a relação entre Direitos Humanos e Educação Ambiental e Direitos humanos, no Assentamento Nova Vida em Pitimbu-PB.

\section{OBJETIVOS ESPECÍFICOS}

- Conhecer o que os jovens do assentamento Vida Nova entendem por Educação Ambiental e Direitos Humanos.

- Identificar dentro do sistema em que os jovens estão inseridos as potencialidades e os pontos de estrangulamento existente no Assentamento Vida Nova.

- Identificar as oportunidades e ameaças existentes no ambiente em que os jovens do Assentamento Vida Nova.

\section{METODOLOGIA}

O estudo foi realizado no Assentamento Nova Vida, situado no Munícipio de Pitimbu, que esta inserido na microrregião do litoral Sul da Paraíba, Brasil. A pesquisa foi realizada com jovens entre 15 e 29 anos que residem no assentamento, durante o ano de 2003, sendo realizadas três visitas.

Nos assentamentos rurais de Pitimbu/PB, várias são as iniciativas de ações sociais, comunitárias, envolvendo a educação ambiental de crianças e adultos. Aplicado a GESPAR Plano de Gestão participativa, uma metodologia utilizada para o diagnóstico e levantar das demandas locais, tal levantamento utilizando atores locais sejam eles, autoridades, Governo e sociedade civil organizada ou não. Esta metodologia foi criada pelo PNUD (Programa das Nações Unidas para o Desenvolvimento) e visa facilitar a administração pública e privada nos problemas locais que muitas vezes, não se consegue diagnosticar de maneira eficaz, e tornando a administração descentralizada e participativa, dentro desse sistema foram analisadas.

Os encontros aconteciam na Escola da Comunidade Sede Velha, Pitimbu das 08:00 ás 17:00. Nos dias de sábado. Os mesmos tiveram ainda a participação dos técnicos do Para'iwa, um representante do INCRA, um representante do MST e representantes legais das Comunidades participantes. Projeto de preservação, sensibilização, educação e luta pela 
proteção dos recursos de subsistência das comunidades participantes. Potencialidades - são elementos que estão inseridos no Sistema, e fazem parte dos pontos positivos da localidade. As identificações são necessárias para que sejam desenvolvidas ações e forças advindas da comunidade.

- Pontos de Estrangulamento - elementos inseridos no Sistema, que construam parte dos pontos negativos da localidade, obstáculos ao desenvolvimento da comunidade como um todo necessitam de ações comuns, para sua eliminação.

Dentro do Ambiente duas analises foram realizadas:

- Oportunidades - são elementos positivos externos que interagem com a comunidade, dando oportunidades de formular vantagens comparativas.

- Ameaças - são elementos negativos externos que interagem na comunidade, deixando a única alternativa de proteção, qualificar as ameaças mais significativas, porque é aquele que oferece sensação de impotência, e constitui objetivo ser atingido.

Posteriormente as crianças e adultos eram convidados a escrever em uma cartolina e apresentar ao fim da reunião para todos.

\section{RESULTADOS E DISCUSSÃO}

Quadro demonstrativo das oficinas (GESPAR - Plano de Gestão Participativa) nos assentamentos de Pitimbu/PB.

Tabela 1. Identificação das potencialidades e dos pontos de estrangulamento - Sistemas .

\begin{tabular}{|c|c|c|c|}
\hline \multicolumn{4}{|c|}{ Sistemas } \\
\hline \multicolumn{2}{|c|}{$\begin{array}{c}\text { Potencialidades } \\
\end{array}$} & \multicolumn{2}{|c|}{ Pontos de Estrangulamento } \\
\hline A reserva (fauna e flora) & Associações & O comodismo & $\begin{array}{l}\text { Falta ajuda do poder } \\
\text { Público }\end{array}$ \\
\hline Recursos hídricos & Cooperativas & Falta de recursos & $\begin{array}{l}\text { Desrespeito com a } \\
\text { natureza }\end{array}$ \\
\hline A sede & $\begin{array}{l}\text { Mão-de-obra } \\
\text { especializada local }\end{array}$ & $\begin{array}{l}\text { Pavimentação } \\
\text { (externa e interna) }\end{array}$ & $\begin{array}{l}\text { Uso inadequado do } \\
\text { solo }\end{array}$ \\
\hline $\begin{array}{l}\text { Diversidade de Culturas } \\
\text { (lendas) }\end{array}$ & Educação & $\begin{array}{l}\text { Falta de recursos para } \\
\text { a reforma da sede }\end{array}$ & $\begin{array}{l}\text { Falta assistência } \\
\text { técnica rural }\end{array}$ \\
\hline Pecuária & Orla marítima & As queimadas & Falta infraestrutura \\
\hline Agricultura & Chuvas & $\begin{array}{l}\text { Desmatamentos dos } \\
\text { manguezais }\end{array}$ & Falta capacitação \\
\hline Energia & Água encanada & Falta de higiene & \\
\hline Plantas medicinais & $\begin{array}{l}\text { Conselho de } \\
\text { desenvolvimento rural }\end{array}$ & $\begin{array}{l}\text { Falta de Estrutura na } \\
\text { educação }\end{array}$ & \\
\hline Escola & Fertilidade do solo & Resíduos químicos & \\
\hline Artesanato & Água encanada & Estradas ruins & \\
\hline Frutas & Caprinocultura & $\begin{array}{l}\text { Erosão (causada pela } \\
\text { PB 008) }\end{array}$ & \\
\hline Consciência ambiental & Avicultura & $\begin{array}{l}\text { Poluição (destilaria } \\
\text { Tabú) }\end{array}$ & \\
\hline $\begin{array}{l}\text { Capacitação em defensivos } \\
\text { agrícolas }\end{array}$ & Piscicultura & $\begin{array}{l}\text { Falta de conselho } \\
\text { ambiental }\end{array}$ & \\
\hline
\end{tabular}


Tabela 2. Identificação das oportunidades e ameaças - ambiente.

\begin{tabular}{|c|c|c|c|}
\hline \multicolumn{4}{|c|}{ Ambiente } \\
\hline \multicolumn{2}{|c|}{ Oportunidade } & \multicolumn{2}{|c|}{ Ameaças } \\
\hline Curso de informática & Ensino fundamenta & Calda de usina & Agrotóxicos \\
\hline Fóruns & Encontros & $\begin{array}{l}\text { A redinha do } \\
\text { caranguejo }\end{array}$ & O atravessador \\
\hline Chuvas & Artes & Falta de consciência & Desmatamento \\
\hline Financiamentos & Oficina de trabalho & Queimadas & $\begin{array}{l}\text { Políticas públicas } \\
\text { falhas }\end{array}$ \\
\hline $\begin{array}{l}\text { Capacitação para proteção } \\
\text { do ambiente }\end{array}$ & Prefeitura & $\begin{array}{ll}\text { Poluição } & \text { do } \\
\text { ecossistema } & \end{array}$ & $\begin{array}{l}\text { Deficiência da } \\
\text { representatividade }\end{array}$ \\
\hline ONGs & Cursos & $\begin{array}{l}\text { Falta de assistência } \\
\text { técnica }\end{array}$ & Alcoolismo \\
\hline Emater & СРТ & & \\
\hline MST & Conquista da terra & Falta de crédito & \\
\hline $\begin{array}{l}\text { Reuniões com } \\
\text { público }\end{array}$ & Reflorestamento & & \\
\hline
\end{tabular}

Na Tabela 1, o grupo formado por jovens, identificou as potencialidades existentes no ambiente em que vivem, assim como, atividades que podem ser desenvolvidas por eles e contribuir para a manutenção da sustentabilidade no assentamento. As características enumeradas por eles podem ser divididas em tecnologias como caprinocultura, avicultura, piscicultura, capacitação em defensivos agrícolas; práticas sociais como o desenvolvimento do conselho rural e a educação.

Esta tomada de consciência corrobora com (BRASIL, 2012), pois afirma que o desenvolvimento sustentável tem como base a atuação da tecnologia, práticas sociais e a educação. De uma forma bem simples através das características apresentadas pelos jovens é possível compreender que eles compreendem a importância.

Ainda na Tabela 1, quando observado os pontos de estrangulamento, citados pelos jovens, na lista apresentada por eles estão presentes características que fazem parte do assentamento Vida Nova. Contudo, estão presentes também caraterísticas pertencentes ao meio externo ao que vivem dentre elas podemos citar a falta de higiene e o comodismo, estes são problemas de fácil solução. No entanto, alguns pontos de estrangulamento citados como a falta de assistência técnica e de concelho ambiental, poluição (destilaria Tabu), erosão causada pela PB 008, a falta de ajuda por parte do poder público, entre outros, cujo controle e a mitigação dos impactos dependem da iniciativa de politicas públicas voltadas para agricultura familiar.

Na Tabela 2 quando os jovens apresentam as oportunidades estão presentes as mesmas características fatores que fazem parte do assentamento e fatores externo ao assentamento. Contudo, há uma predominância de fatores externos 87,5 \% em detrimento aos fatores que fazem parte do assentamento $12,5 \%$. Dentre os fatores presentes no assentamento é possível citar: chuva e reflorestamento, apenas comparados aos fatores externos como: cursos, conquista da terra, MST, Comissão Pastoral da Terra - CPT, ONGs entre outros. Quando os jovens relataram as oportunidades, não houve um reconhecimento do que a natureza pode oferecer, sendo predominantes as características presentes na política, de forma que todas as oportunidades oferecidas pelo ambiente são ignoradas. Este fato corrobora com Jacobi (2003), pois afirma que a reflexão a respeito de práticas sociais, que ocorre em um contexto onde há degradação do meio ambiente e, por conseguinte do ecossistema, necessita de uma articulação com a produção de sentidos a respeito da educação ambiental. 
Quando relatado as ameaças o mesmo padrão se apresenta, $25 \%$ dos fatores apresentados como ameaças estão relacionados aos impactos gerados pelos assentados e $75 \%$ não depende diretamente dos assentados. Dentre os fatores ligados diretamente as pessoas que residem no assentamento é possível citar o alcoolismo e falta de consciência. Comparados aos fatores externos estes não dependem diretamente das pessoas que vivem no assentamento como: a deficiência na representatividade e falta de crédito, poluição do ecossistema, politicas públicas falhas entre outros. Este resultado corrobora com o estudo de Machado (1998), pois em seu estudo afirma que a questão ambiental só será considerada pela pelas pessoas que vivem no assentamento quando for realizado um processo amplo de reflexão/ação a respeito das atuais práticas sociais e produtivas.

\title{
Interdisciplinaridade em Educação Ambiental
}

Interdisciplinaridade em Educação Ambiental é uma premissa básica da sustentabilidade, pois a vida em todas as suas formas de expressão manifesta-se como interdependência de fenômenos. Pode se dizer que nela a integração e a interação são fundamentais para efetivação da interdisciplinaridade dos temas ambientais. Segundo Fazenda (1993, p. 8):

A primeira condição de efetivação da interdisciplinaridade é o desenvolvimento da sensibilidade, neste sentido tornando-se particularmente necessária uma formação adequada que pressuponha um treino na arte de entender e esperar, um desenvolvimento no sentido da criação e da imaginação.

A educação ambiental não é uma construção abstrata em si não há singularidade conceitual que possa explicar seu universo particular, ao qual ela possa fazer referência. São práticas de educação ambiental, experimentadas na particularidade de cada realidade comunitária especifica independentemente das dimensões dessa comunidade, que constroem conceitos, atitudes, soluções, "jeitos”, e alternativas provadas de um fazer. Segundo Cascino (1999 p. 68-69):

\begin{abstract}
A ação interdisciplinar estabelecerá, junto das práticas docentes e do desenvolvimento do trabalho didático-pedagógico - na transmissão e reconstrução dos conteúdos disciplinares - a construção do "ser-no-outro", ou a experiência de transformar-se no diferente/outro. Essa lógica revela o ponto de partida para o processo interdisciplinar. Assim não se trata de simples cruzamento de "coisas parecidas; trata-se, bem ao contrário, de constituir diálogos fundados na diferença, abraçando concretamente a riqueza derivada da diversidade."
\end{abstract}

Conscientes desta condição, educadores e ambientalistas hoje podem inaugurar uma nova etapa desse caminhar. Engendrar uma eco pedagogia, que procure dar conta de assumir as questões ambientais, seu elementos reflexivos e práticas militantes, incorporando-os às teorias e práticas curriculares, encontrando ai elementos substanciais de transformação das matrizes disciplinares, clivando o cotidiano escolar com novas leituras e conteúdos sustentados em linguagens diversificadas, buscando, efetivamente, transversalizar conhecimentos, interdisciplinarizando-os, eis a tarefa que aguarda educadores, militantes, e todos aqueles que lutam por "outro" meio ambiente.

De forma geral, o meio ambiente apresenta três dimensões interdependentes: ele é provedor de recursos naturais e receptores de todo tipo de dejetos resultantes do processo socioeconômico; também é o espaço onde acontecem as realizações socioambientais; finalmente ele é habitat, que envolve, entre outros aspectos, as atividades produtivas e de lazer. Estas dimensões, muito embora não sejam percebidas no âmbito da regulação político-econômica, afetam as condições de reprodução da vida social e, de forma mais abrangente, a qualidade de 
vida da população. Para Capra (2003) nos ecossistemas, a complexidade da rede é uma consequência da sua biodiversidade e, desse modo, uma comunidade ecológica diversificada é uma comunidade elástica. No entanto, a diversidade só será uma vantagem estratégica se houver uma comunidade realmente vibrante, sustentada por uma teia de relações.

O importante é ensinar e educar a todos sobre a importância de se preservar e cuidar do meio ambiente em que vivemos independentes de nossas origens étnicas, credos, níveis socioeconômicos, visões de mundo, entre outros, pois o planeta em que habitamos é apenas um só. Imaginemos que ele é uma nave espacial que está sempre viajando pelas estrelas, carregando consigo uma ampla diversidade de formas de vida e, entre elas, a espécie humana. Porém, a população humana cresce cada vez mais, degradando o interior da nave, inviabilizando de certa forma os sistemas de suporte vital e, como sabemos os recursos são finitos e diminuem a cada dia que passa.

\section{CONSIDERAÇÕES FINAIS}

A educação ambiental proposta neste artigo não está apenas vinculada à transmissão de conhecimentos sobre a natureza, mas sim à possibilidade de participação social de todos os membros desse planeta, conscientes de seus direitos e deveres. Para tanto, é preciso, pois, que desenvolvamos outro modo de pensar e de agir, que incorpore outra relação com a natureza e demais membros dessa diversidade da qual somos todos interdependentes. Até porque, como vimos à educação ambiental e os meios preservacionistas que ela proporciona constituem uma questão que envolve também os direitos humanos, pois concerne ao respeito à dignidade humana e a uma melhor qualidade de vida para os assentados e demais os indivíduos. Assim, é necessário que, além de compreender o mundo em toda sua complexidade, possamos criar melhores condições de vida neste planeta, para as atuais e futuras gerações; que possamos, enfim, viver com dignidade, respeito e melhor qualidade de vida.

\section{REFERÊNCIAS}

ALENCAR, C. (Org.). Direitos mais humanos. São Paulo: Garamond, 1999.

BRASIL. Ministério do Meio Ambiente. Secretaria de Articulação Institucional e Cidadania Ambiental. Boas Práticas em educação Ambiental na Agricultura Familiar. Brasília: MMA, 2012.

CAPRA, F. O ponto de mutação: a Ciência, a sociedade e a cultura emergente. 24. ed. São Paulo, Cultrix, 2003.

CASCINO, F. Educação ambiental: princípios, história, formação de professores. 2. ed. São Paulo: SENAC, 2000.

CERQUEIRA, W. Aprendendo a amar: para gostar de verdade. São Paulo, 2001.

DIAS, G. F. Educação ambiental: princípios e práticas. 5. ed. São Paulo: Gaia, 1998.

FAZENDA, I. C. A. Integração e interdisciplinaridade no ensino brasileiro: efetividade ou ideologia. 3. ed. São Paulo: Loyola, 1993.

FERREIRA, N. T. Cidadania: uma questão para educação. 7. ed. Rio de Janeiro: Nova Fronteira, 2002.

LEÃO, A. L. C.; SILVA, L. M.A. Fazendo Educação Ambiental. 4. ed. rev. atual. Recife: Publicações CPRH, 1999. (Biblioteca Pernambuca de Meio Ambiente, 002). 
FREIRE, P. Pedagogia da autonomia: saberes necessários á prática educativa. 14. ed. São Paulo: Paz e Terra, 2000.

GOHN, M. G. Movimentos e lutas sociais na História do Brasil. São Paulo: Loyola, 1995.

GONÇAL VES, C. W. P. Os (Des)Caminhos do Meio Ambiente. São Paulo: Contexto, 2002.

JACOBI, P. Educação Ambiental, Cidadania e Sustentabilidade. Rev. Cadernos de Pesquisa, n. 118, p. 189-205. 2003.

MACHADO, A. M. B. Educação ambiental para desenvolvimento sustentável em assentamentos rurais: contribuições de um estudo de representações sociais. Cadernos de Ciência \& Tecnologia, v. 15, n. 1, p. 125-136, 1998 . Disponível em: $<$ http://www.alice.cnptia.embrapa.br/bitstream/doc/312075/1/Maciel.pdf>. Acesso em: 24 mar. 2016.

NEVES, E.; TOSTES, A. Meio Ambiente a Lei em suas mãos. Petrópolis: Vozes, 1998.

RUSCHEINSKY, A. (Org.). Educação ambiental: abordagens múltiplas. Porto Alegre: Artmed, 2002.

SÁNCHEZ, S. S. S. Cidadania ambiental: novos direitos no Brasil. São Paulo: Humanitas, 2000.

SECRETARIA NACIONAL DOS DIREITOS HUMANOS. Política Nacional do Idoso. Declaração Universal dos Direitos Humanos. Programa Nacional de Direitos Humanos. Brasília: Secretaria Nacional dos Direitos Humanos, 1998.

TEDESCO, J. C. O novo pacto educativo, educação, competitividade e cidadania na sociedade moderna. São Paulo: Ática, 1998. 